\title{
Probability Analysis of Island Distribution at the Early Stage in Electrodeposition Based on a Fixed Length Segment Model
}

\author{
M. Saitou \\ Department of Mechanical Systems Engineering, University of the Ryukyus, 1 Senbaru Nishihara-cho \\ Okinawa, 903-0213, Japan \\ E-mail: saitou@tec.u-ryukyu.ac.jp
}

doi: $10.20964 / 2016.09 .40$

Received: 7 June 2016 / Accepted: 11 July 2016 / Published: 7 August 2016

\begin{abstract}
A fixed length segment model that describes a random distribution of segments that have a fixed number of sites at which islands can nucleate is proposed. The model is based on observations of several metal islands aligned without gaps on a curved line at the early stage in electrodeposition. The model has the advantage of being able to calculate analytically the number of two, three, and four islands aligned without gaps on the segment. In addition, the two-dimensional distribution of the segment derived analytically yields the limiting radius of the island beyond which the island cannot grow with time. The analytical results such as the expected value of the number of the two, three, and four islands and the limiting radius of the island are well consistent with the copper island distribution electrodeposited on an ITO glass at the early stage using a solution of copper (II) sulfate pentahydrate and potassium sodium tartrate. The characterization of the ITO glass surface as a nucleation site is demonstrated using the fixed length segment model.
\end{abstract}

Keywords: probability, fixed length segment model, islands aligned without gaps, segment distribution, limit radius, copper electrodeposition

\section{$\underline{\text { FULL TEXT }}$}

(C) 2016 The Authors. Published by ESG (www.electrochemsci.org). This article is an open access article distributed under the terms and conditions of the Creative Commons Attribution license (http://creativecommons.org/licenses/by/4.0/). 